\title{
Computational Characterization of Fluid Flow and Heat Transfer in the Pressure Tube of CANDU 6 Nuclear Reactor with Supercritical $\mathrm{CO}_{2}$
}

\author{
Lakshmana Kishore. $\mathrm{T}^{\# 1}$, Dr. Kiran Chaudhari ${ }^{* 2}$, Dr. G. Ranga Janardhana ${ }^{\# 3}$ \\ ${ }^{\# 1}$ Assistant Professor of Mechanical Engineering, JNTUK University College of Engineering, Vizianagaram \\ ${ }^{* 2}$ Professor of Mechanical Engineering, MCT's Rajiv Gandhi Insitute of Technology, Mumbai \\ \#3 Professor of Mechanical Engineering, JNTUA University college of Engineering, Anantapuramu \\ ${ }^{1}$ kishore.me@jntukucev.ac.in \\ 2mkiran02@rediffmail.com \\ 3 ranga.janardhana@gmail.com
}

Abstract - The heat transfer and fluid flow analysis of the pressure tube in the primary circuit of CANDU 6 nuclear reactor is performed by using Supercritical fluids (SCF's) as working fluid. Currently available CANDU 6 nuclear reactor uses heavy water as the working fluid in the primary circuit. In order to increase the heat transfer and for better performance, supercritical fluids (SCF's) are selected as the working fluid. The supercritical fluid used is carbon-dioxide $\left(\mathrm{CO}_{2}\right)$. Heavy water is used as the moderator. The pressure tube of the reactor is modelled and analysis is performed using ANSYS-CFX. The solution of the problem is validated using heavy water as working fluid. The pressure drop, velocity variations and the various factors affecting the heat transfer are analysed for the supercritical fluid selected and comparison is made between them.

Keyword - CANDU 6, Super Critical Fluids (SCF’s), Pressure Tube, Nuclear Reactor.

\section{INTRODUCTION}

The CANDU 6 Nuclear Reactor is using Heavy Water as the working fluid. In this paper the pressure tube of the Nuclear Reactor is studied using Supercritical Carbon-dioxide as the working fluid. The dimensions of the pressure tube taken, are same as that of the CANDU 6 Nuclear Reactor.

\section{A. CANDU 6 Nuclear Reactor Pressure Tube}

CANDU 6 is the Generation III, 600 MW class heavy-water moderated and cooled pressure tube reactor. Heavy water $\left(\mathrm{D}_{2} \mathrm{O}\right)$ is a natural form of water that is used as a moderator to slow down the neutrons in the reactor, enabling the use of natural uranium as fuel. Same $\mathrm{D}_{2} \mathrm{O}$ is used as the working liquid, responsible for transportation of heat. The dimensions used in the analysis is taken from [1] and [2].

Concept of nuclear reactors with water at supercritical pressures were studied as early as the 1950s and 1960s in the USA and Russia. Similar to the CANDU design, the CANDU-SCWR is moderated with Heavy water. The coolant used is light water at 25 Mpa pressure and with an inlet temperature of $350^{\circ} \mathrm{C}$. With SCF's as a coolant the efficiency increased to over $40 \%$ [9].

\section{B. Supercritical Fluid}

Supercritical fluid is any substance at a pressure and temperature above its critical point, where distinct liquid and gas phases do not exist. Supercritical fluids combine useful properties of gas and liquid phases. Their behaviour is near gas from some aspects and near liquid in terms of different features. A supercritical fluids provides a gas like characteristic when it fills a container and it takes the shape of container. The motion of molecules are quite similar to gas molecules. On the other hand, a supercritical fluid behaves like a liquid because its density property is near liquid and, thus supercritical fluid shows a similarity to liquid in terms of dissolving effect. The formation of a supercritical fluid is the result of dynamic equilibrium.

When a material is heated until its specific critical temperature in a closed system, which means at constant pressure, a dynamic equilibrium is generated. This equilibrium includes the same number of molecules coming out of liquid phase to gas phase by gaining energy and going into liquid phase from gas phase by losing energy.

At this particular point, the phase curve between liquid and gas phases disappear and supercritical material appears. 


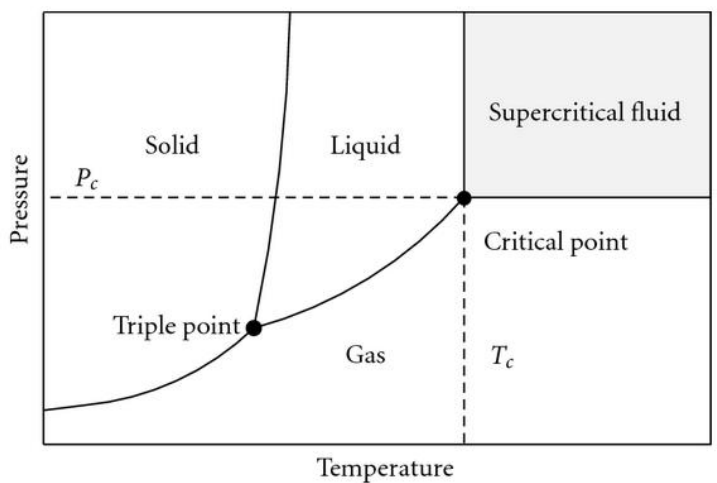

Fig 1: Pressure Vs Temperature for a supercritical fluid

In the phase diagram, the field above critical temperature and critical pressure values is defined as supercritical region. The characteristic properties of a supercritical fluid are density, diffusivity and viscosity. Supercritical values for these features take place between liquids and gases

\section{MODELLING OF THE PRESSURE TUBE}

From [1] the dimensions of the pressure tube of the CANDU 6 Nuclear Reactor is modelled using CATIA V5. The pressure tube contains 12 fuel bundles and each fuel bundle contains 37 fuel rods. The modelled fuel bundle is shown in the figure

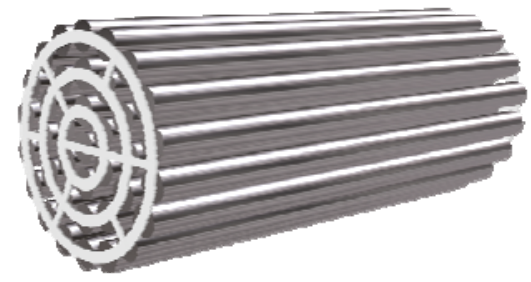

Fig 2: Modelled Fuel bundle in CATIA-V5

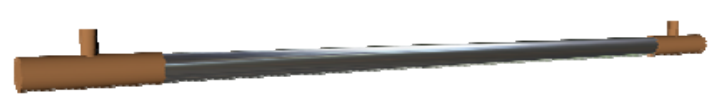

Fig 3: Modelled Pressure Tube in CATIA-V5

There are total of 380 such pressure tubes forming the core of a nuclear reactor, through which heat addition takes place. The modelled pressure tube is imported to ANSYS-CFX for the analysis using different fluids.

\section{III.VALIDATION OF THE PROBLEM}

The pressure tube imported is solved in ANSYS-CFX using Heavy Water as the working fluid and compared with the existing results [3]. The property values of the Heavy Water are taken from [4] \& [5], the boundary conditions applied are taken from [1] and their values are given in table 1 and 2 respectively.

TABLE I. Properties of Heavy Water

\begin{tabular}{|c|c|}
\hline Property & Value \\
\hline Molar Mass (g/mol) & 20.0276 \\
\hline Critical Temperature (K) & 643.89 \\
\hline Critical Pressure (MPa) & 21.67 \\
\hline Critical Volume (cm $\left.{ }^{3} / \mathrm{mol}\right)$ & 56.3 \\
\hline Acentric Factor & 0.364 \\
\hline Boiling Point (K) & 374.57 \\
\hline
\end{tabular}


TABLE 2. Boundary conditions for the pressure tube using Heavy Water

\begin{tabular}{|c|c|}
\hline Boundary Condition & Value \\
\hline Operating Pressure (MPa) & 10.5 \\
\hline Outlet Pressure (MPa) & 0 \\
\hline Mass Flow inlet (kg/s) & 23.9 \\
\hline Inlet Temperature (K) & 539.15 \\
\hline Heat Flux (per bundle) (MW) & 9.6 \\
\hline
\end{tabular}

The ANSYS-CFX result using Heavy Water matches well with the existing results. The comparison and the error percentage is given in table 3.

TABLE 3. Comparison of outlet parameters for validation

\begin{tabular}{|c|c|c|c|}
\hline Property & Values from analysis & Values from [3] & Error Percentage \\
\hline Inlet Pressure $(\mathrm{MPa})$ & 11.0529 & 11.04 & 0.117 \\
\hline Outlet Temperature $(\mathrm{K})$ & 586.975 & 583.15 & 0.656 \\
\hline Density at Inlet $\left(\mathrm{kg} / \mathrm{m}^{3}\right)$ & 795.607 & 782.9 & 1.62 \\
\hline Density at Outlet $\left(\mathrm{kg} / \mathrm{m}^{3}\right)$ & 699.442 & 692.4 & 1.017 \\
\hline
\end{tabular}

With reference to the above table present model is considered to be validated.

\section{IV.ANALYSIS USING SUPERCRITICAL CARBON-DIOXIDE}

The validated model of the pressure tube is now used to do the analysis using Supercritical Carbon-dioxide as the working fluid. The property values of the Supercritical Carbon-dioxide are taken from [4] \& [5].

The property values which are given as input in ANSYS-CFX is represented in table 4 .

TABLE 4. Properties of Supercritical Carbon-dioxide

\begin{tabular}{|c|c|}
\hline Property & Value \\
\hline Molar Mass (g/mol) & 44.01 \\
\hline Critical Temperature (K) & 304.1282 \\
\hline Critical Pressure (MPa) & 7.3773 \\
\hline Critical Volume $\left(\mathrm{cm}^{3} / \mathrm{mol}\right)$ & 94 \\
\hline Acentric Factor & 0.22394 \\
\hline Boiling Point $(\mathrm{K})$ & 194.75 \\
\hline
\end{tabular}

The boundary conditions applied for the analysis are given in table 5 .

TABLE 5. Boundary conditions for the pressure tube using Supercritical Carbon-dioxide

\begin{tabular}{|c|c|}
\hline Boundary Condition & Value \\
\hline Operating Pressure (MPa) & 7.5 \\
\hline Outlet Pressure (MPa) & 0 \\
\hline Velocity Inlet (kg/s) & 5.83622 \\
\hline Inlet Temperature (K) & 300 \\
\hline Heat Flux (per bundle) (MW) & 9.6 \\
\hline
\end{tabular}

The model is solved using UPWIND Scheme. 


\section{RESUlTS}

After the completion of the analysis for the convergence criteria of $1 \mathrm{e}-05$, the results obtained using carbondioxide as the working fluid are analysed by plotting different contours and different property parameters are compared with the results of the analysis using $\mathrm{D}_{2} \mathrm{O}$ as the working fluid.

\section{A. Contours}

Various contours have been drawn at the cross-section of the fuel bundle and between the fuel bundles

1) Contours at the fuel bundle:
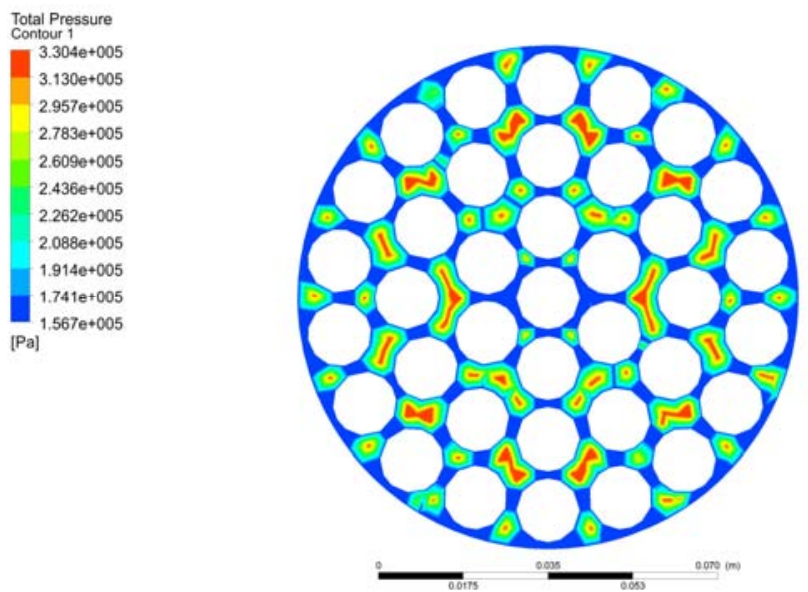

ANSYS

Fig 4: Pressure contours at the fuel bundle
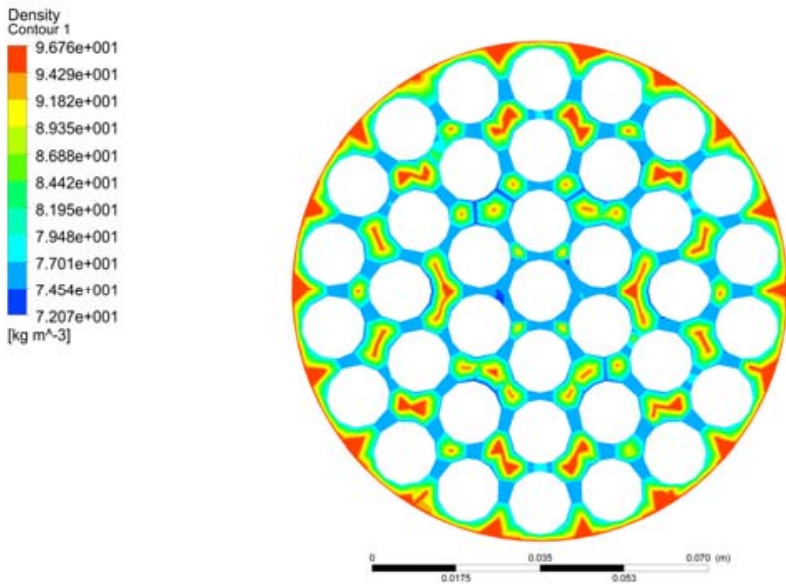

$\underset{\text { ANSYS }}{\text { R1SO }}$

Fig 5: Density contours at the fuel bundle
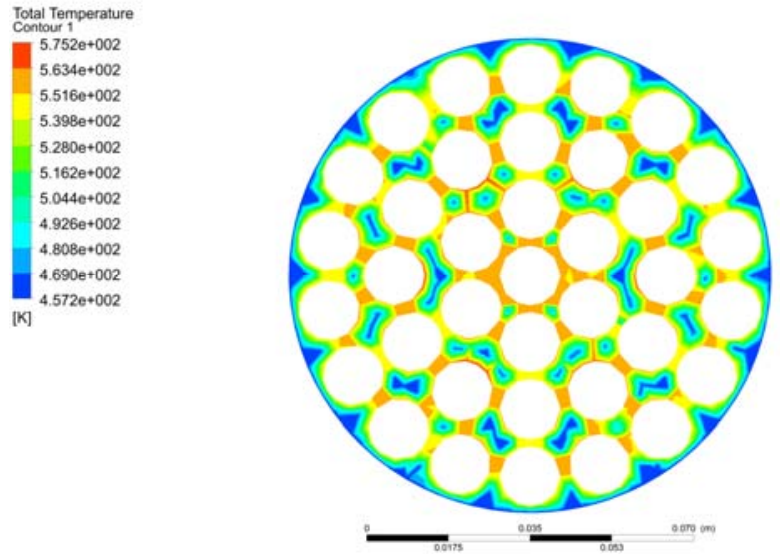

ANSYS

Fig 6: Temperature contours at the fuel bundle 

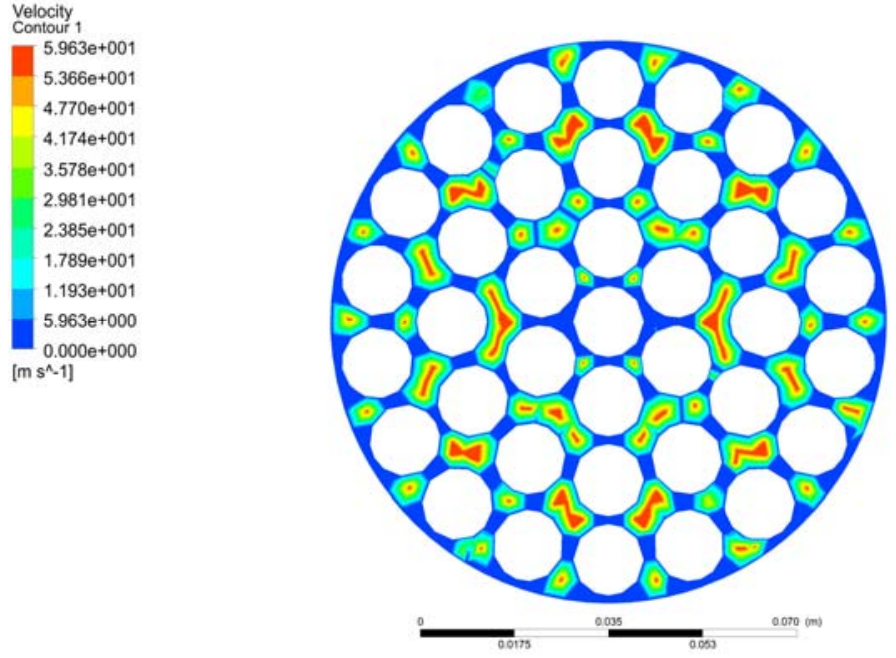

ANSYS

Fig 7: Velocity contours at the fuel bundle

2) Contours at the gap between fuel bundles:
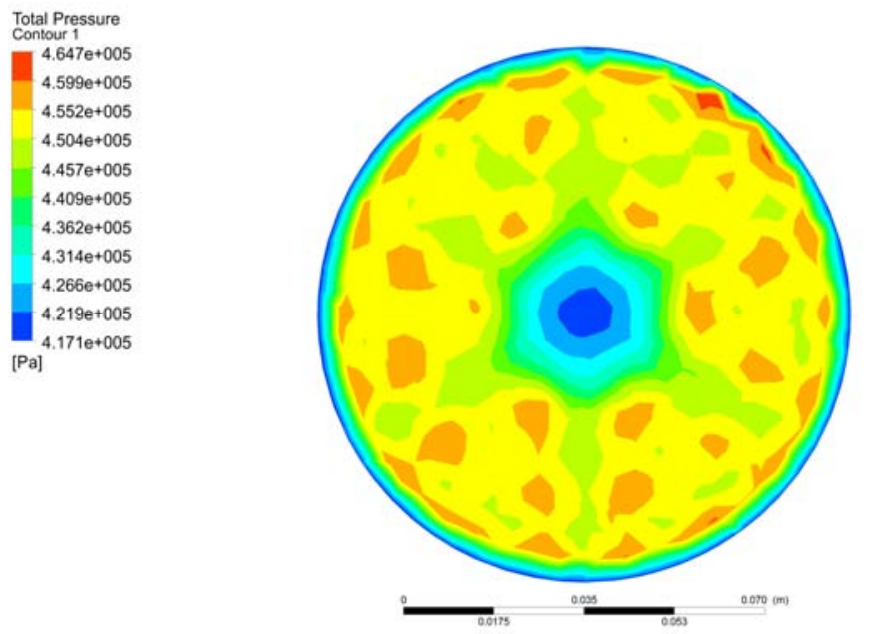

ANSYS

Fig 8: Pressure contours at the gap between fuel bundles

Density
Conlour
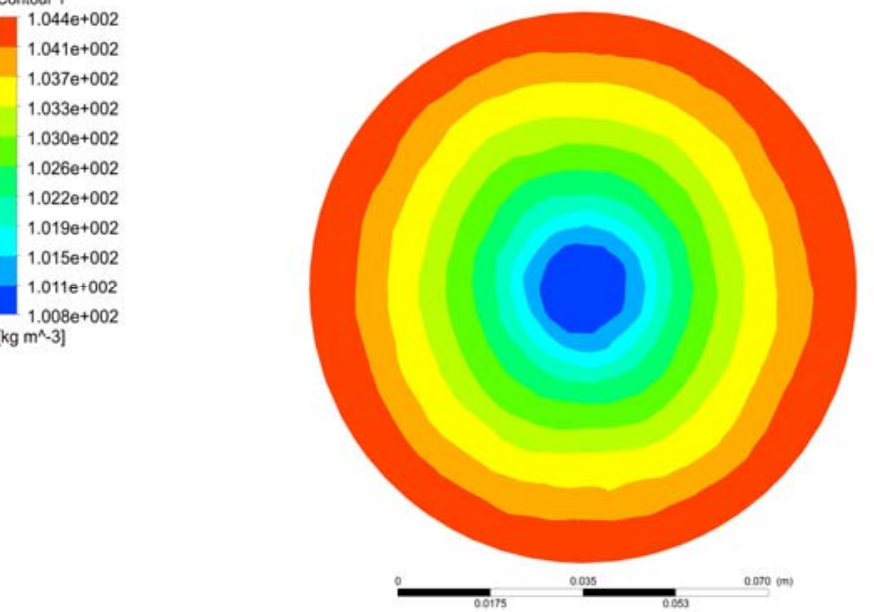

ANSYSS

Fig 9: Density contours at the gap between fuel bundles 

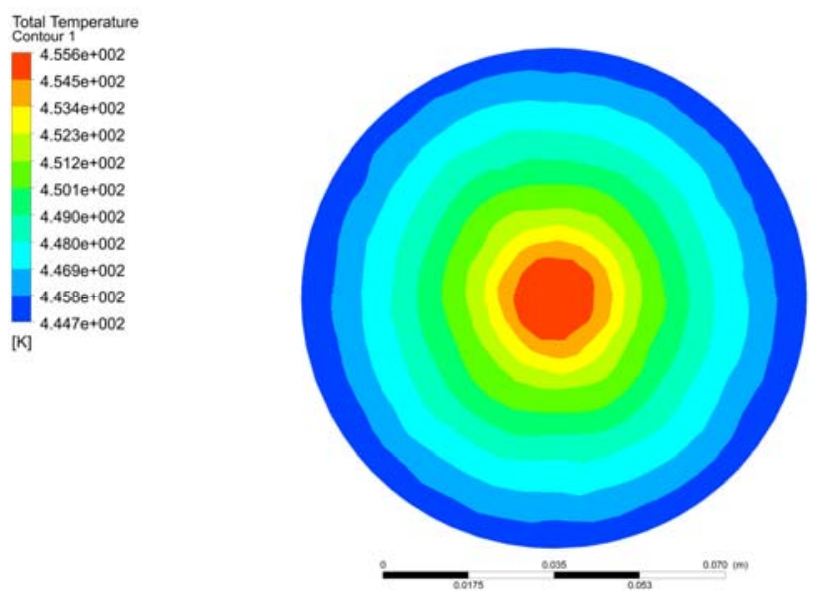

ANSYS

Fig 10: Temperature contours at the gap between fuel bundles
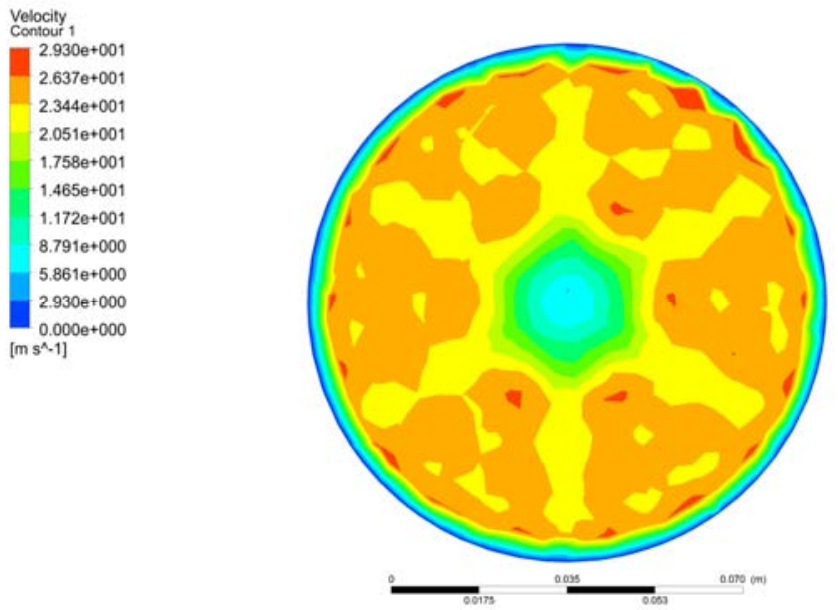

ANSYS

Fig 11: Velocity contours at the gap between fuel bundles

\section{B. Graphs}

Various graphs are drawn comparing the results of the analysis of the pressure tube with Carbon-dioxide and Heavy water as the working fluids.

1) For one fuel bundle (12 th bundle):

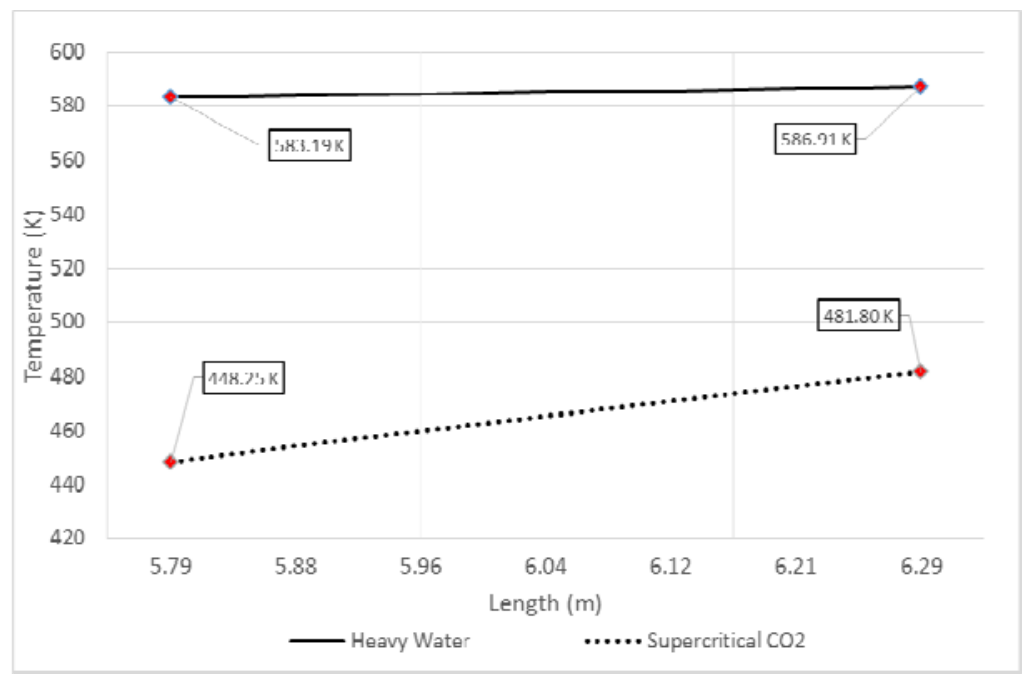

Fig 12: Graph between Temperature Vs Length for the $12^{\text {th }}$ bundle 


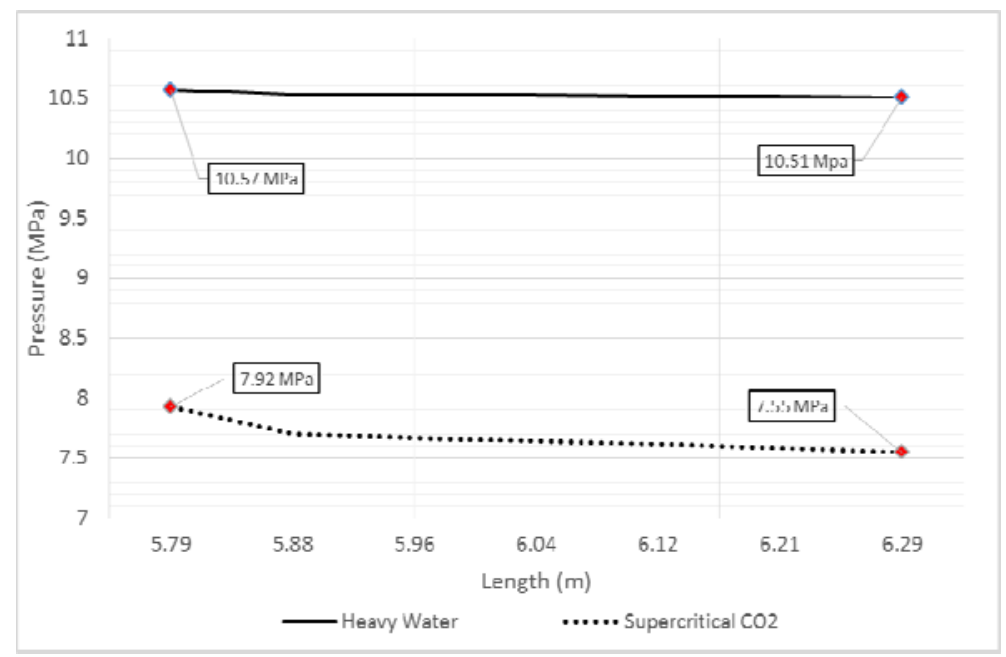

Fig 13: Graph between Pressure Vs Length for the $12^{\text {th }}$ bundle

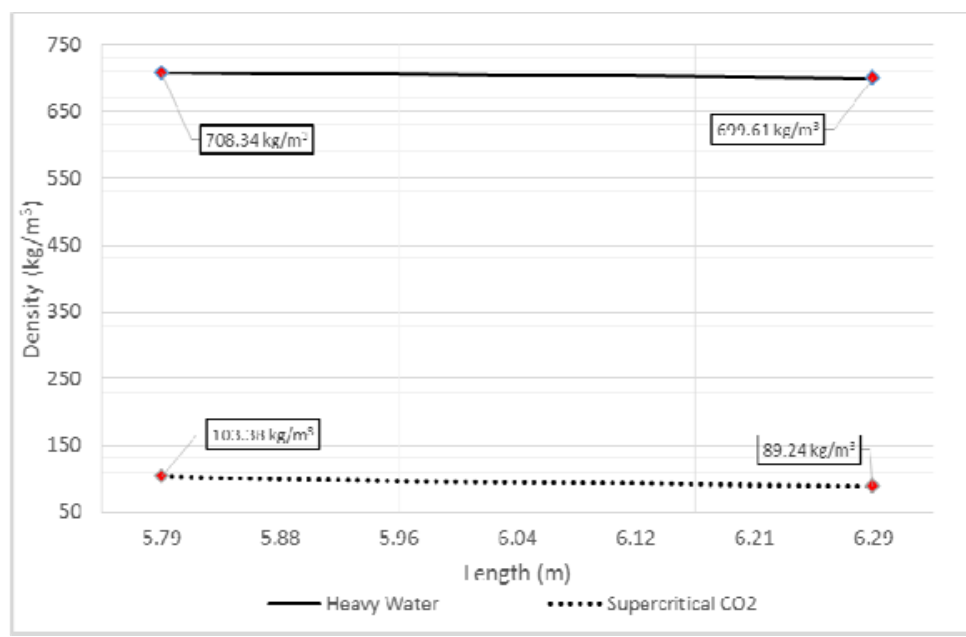

Fig 14: Graph between Density Vs Length for the $12^{\text {th }}$ bundle

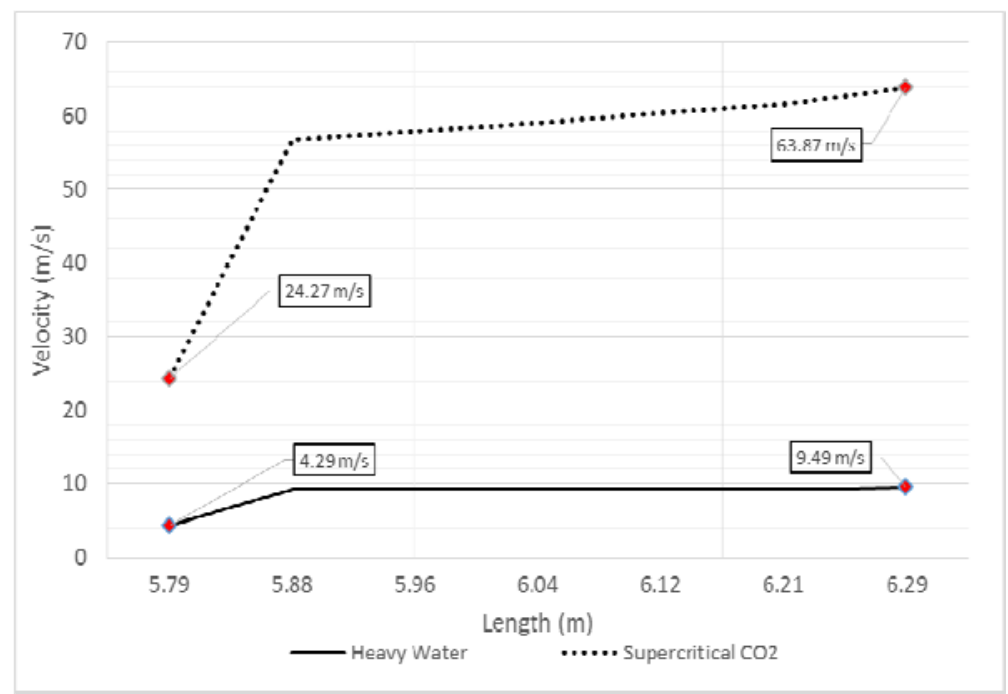

Fig 15: Graph between Velocity Vs Length for the $12^{\text {th }}$ bundle 
2) For the total pressure tube:

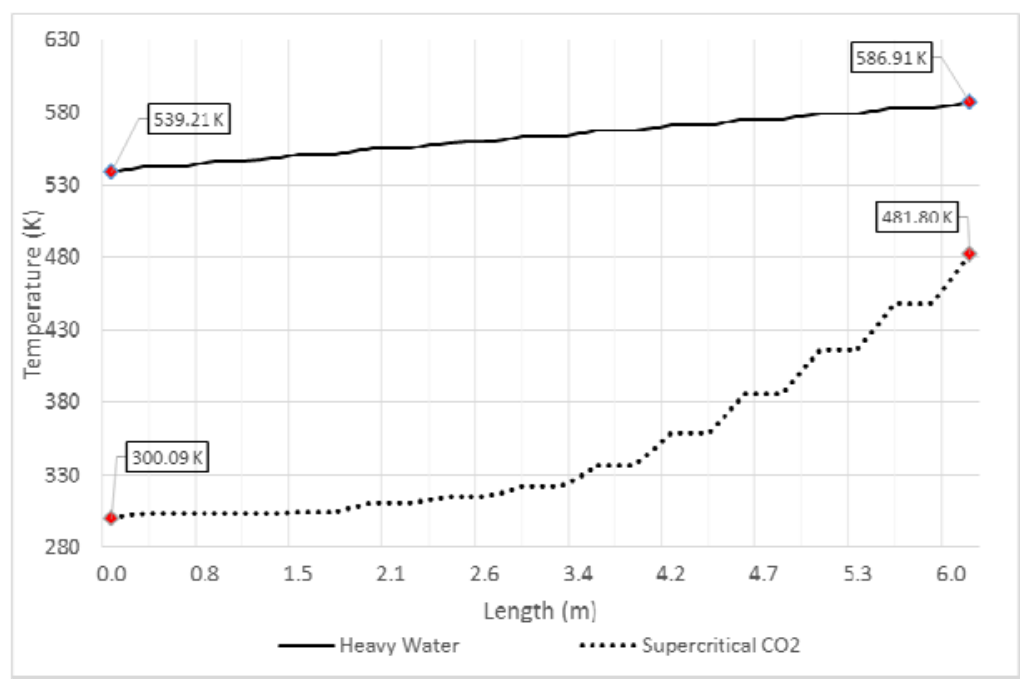

Fig 16: Graph between Temperature Vs Length for the total pressure tube

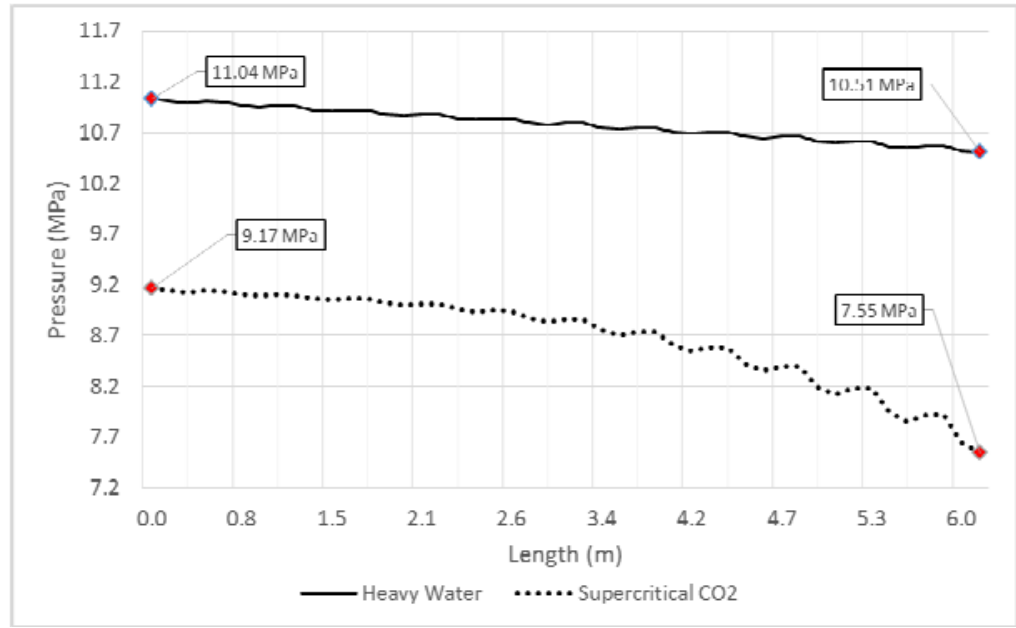

Fig 17: Graph between Pressure Vs Length for the total pressure tube

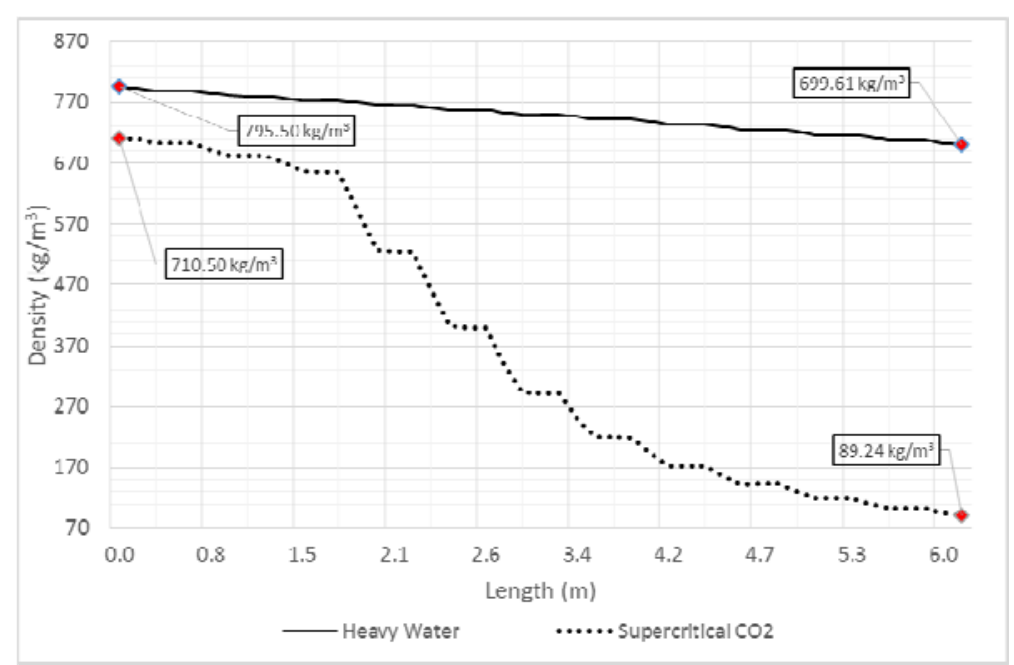

Fig 18: Graph between Density Vs Length for the total pressure tube 


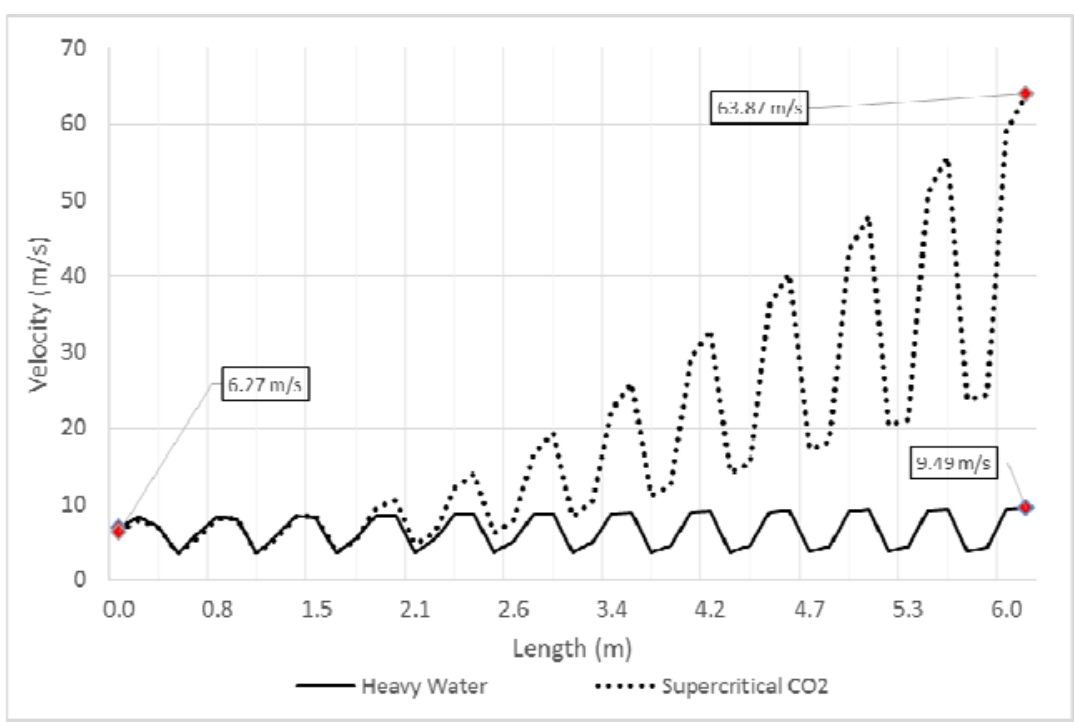

Fig 19: Graph between Pressure Vs Velocity for the total pressure tube

C. Variation of different properties for the pressure tube using Supercritical Carbon-dioxide

Variation of some of the other properties with respect to the length of the pressure tube are plotted below.

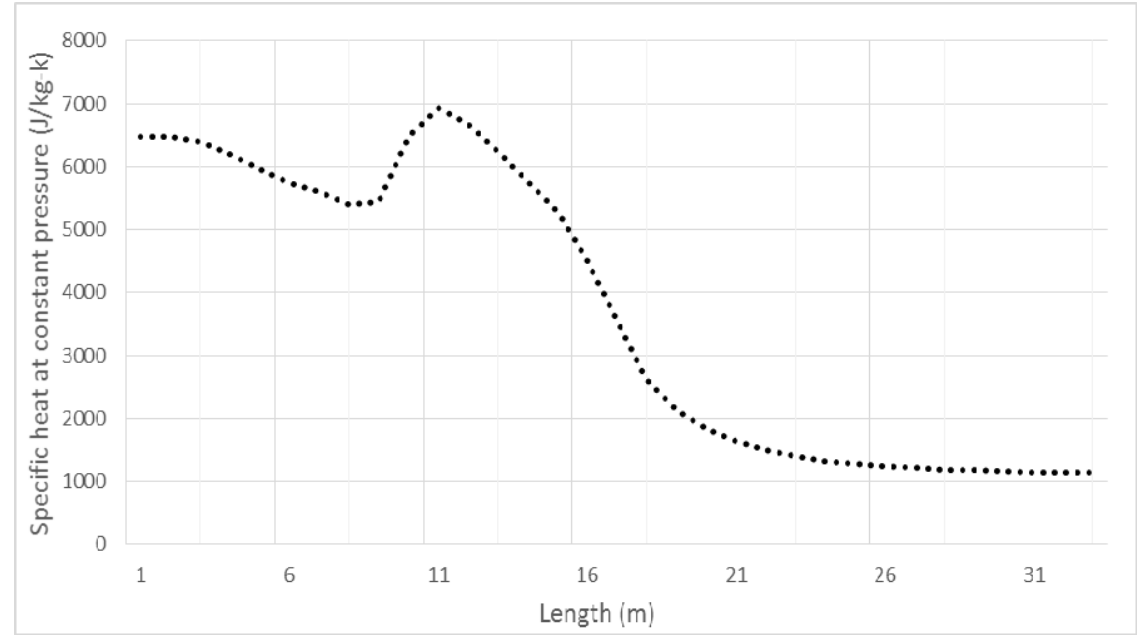

Fig 20: Graph between Specific heat Vs Length for the total pressure tube

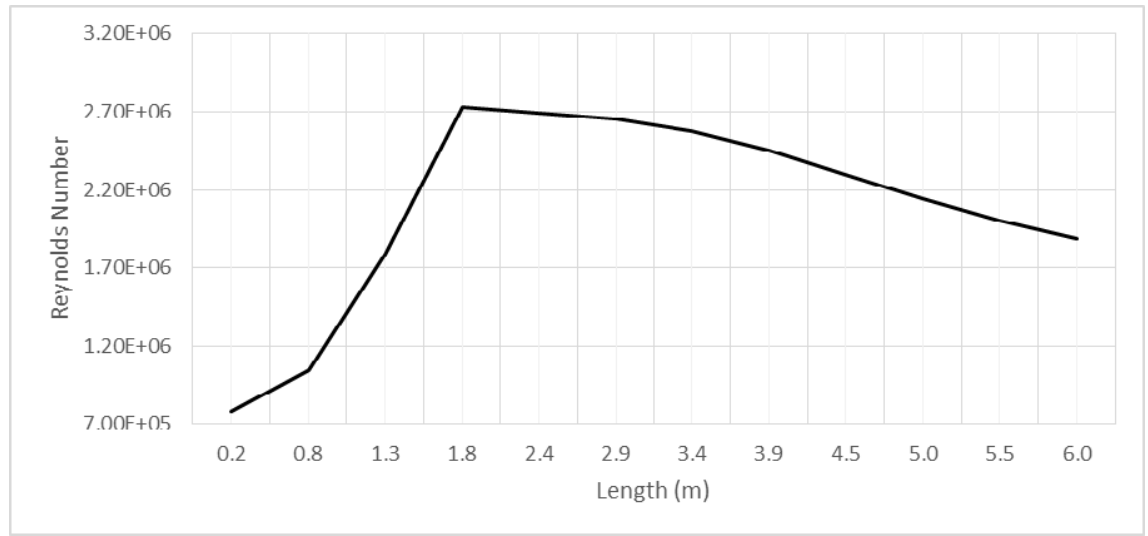

Fig 21: Graph between Reynolds number Vs Length for the total pressure tube 


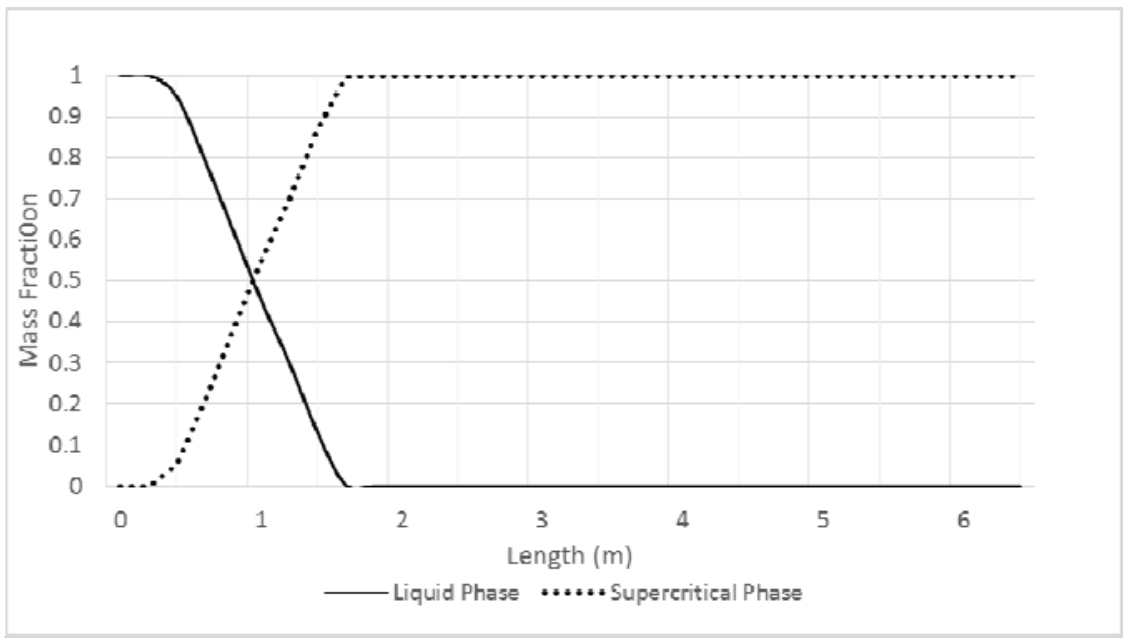

Fig 22: Graph between Mass fraction Vs Length for the total pressure tube

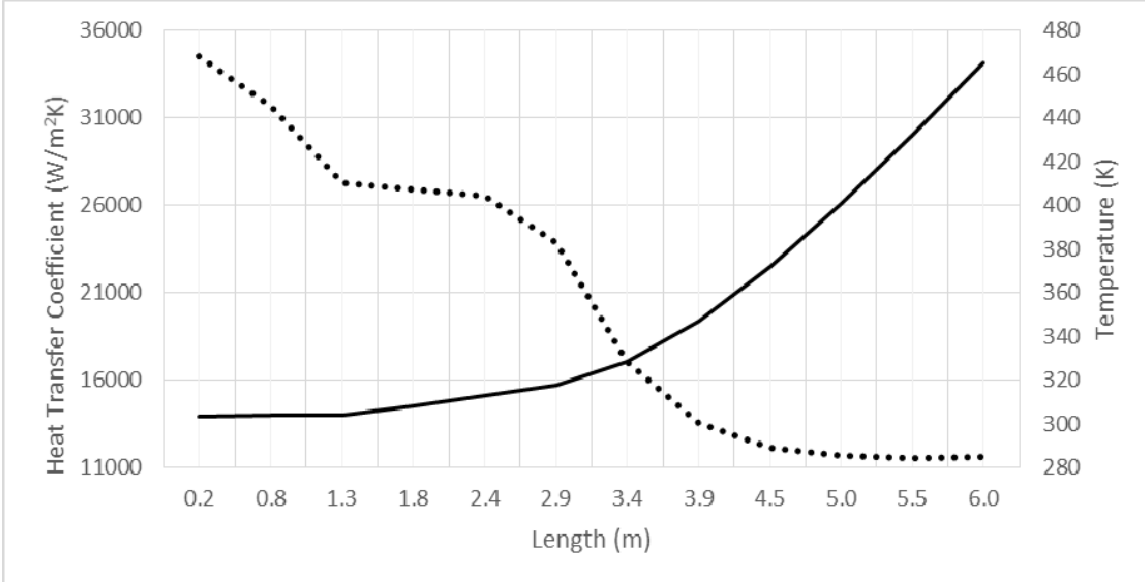

Fig 23: Graph between Heat Transfer Coefficient Vs Length for the total pressure tube

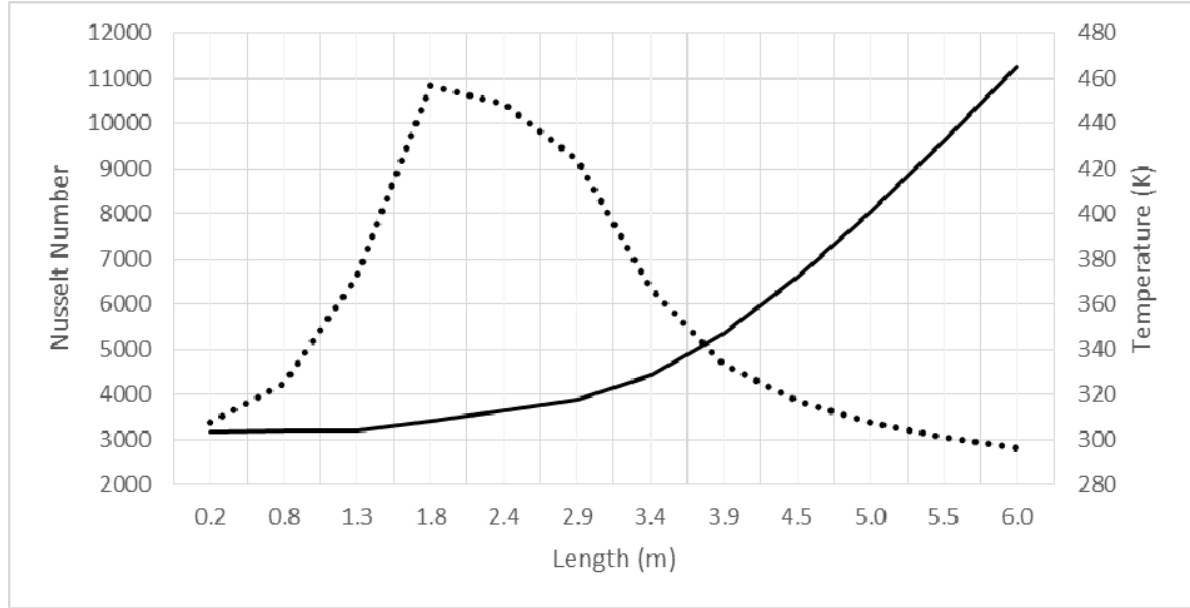

Fig 24: Graph between Nusselt number Vs Length for the total pressure tube

\section{VI.CONCLUSION}

The model of the pressure tube of CANDU 6 Nuclear Reactor created in CATIA V5 is validated with very less error percentage.

With reference to the analysis using Supercritical Carbon-dioxide as the working fluid, more amount of heat transport is done when compared to Heavy Water as the working fluid. In effect the capacity of the Nuclear Reactor can be increased for more power generation. From the fig 18 we can observe that density at outlet of the pressure tube is reducing greatly in case of Carbon-dioxide. Because of this, the mass flow rate is reduced which in turn reduces the size of pump. 
Even though more pressure to be controlled using Supercritical Carbon-dioxide when compared to Heavy Water, mass flow rate of the working fluid is getting reduced for the same inlet velocity. So Supercritical fluids show a vast scope of research in future nuclear reactors.

\section{REFERENCES}

[1] Wm. J. Garland, “A text book on the CANDU Nuclear Power Plant Technology”, The Essential CANDU, ISBN 0-9730040.

[2] Dr. Robin Chaplin, “Genealogy of CANDU Reactors,” The Essential CANDU, Chapter 2, ISBN 0-9730040, Dec., 2016.

[3] Chun K. Chow, and Hussam F. Khartabil, “CONCEPTUAL FUEL CHANNEL DESIGNS FOR CANDU-SCWR,"Nuclear Engineering and Technology, vol.40, Special issue on the $3^{\text {rd }}$ International Symposium on SCWR, Nov. 15, 1999.

[4] NASA Polynomial format for CHEMKIN-II, GRI-Mech Version 3.0 Thermodynamics released 7/30/99.

[5] http://webbook.nist.gov/, @2016.

[6] Alexandru CATANA, Ilie PRISECARU, Daniel DUPLEAC, and Danila NICOLAE, "COMPUTATIONAL FLIUD DYNAMIC APPROACH FOR CANDU6 AND ACR1000 FUEL CHANNEL COOLANT FLOW,” ISSN 1454-2358, U.P.B. Sci. Bull., Series D, Vol. 72, Iss. 1, 2010.

[7] K. Podila, Y.F. Rao, "CFD analysis of flow and heat transfer in Canadian supercritical water reactor bundle,” ELSEVIER, 2014.

[8] Chun K. Chow, and Hussam F. Khartabil, "CONCEPTUAL FUEL CHANNEL DESIGNS FOR CANDU-SCWR,” Nuclear Engineering and Technology, vol.40, Special issue on the $3^{\text {rd }}$ International Symposium on SCWR, Nov. 15, 1999.

[9] R.B. Duffey, I.L. Pioro, B.A. Gabaraev and Yu. N. Kuznetsov, "SCW Pressure-Channel Nuclear Reactors: Some Design Features", the 14th International Conf. on Nuclear Engineering (ICONE-14), Paper 89609, 2006.

[10] T. Schulenberg, L.K.H. Leung, D. Barady, Y. Oka and K. Yamada, "Supercritical Water-cooled Reactor (SCWR) Development through GIF Collaboration”, IAEA-CN-164-5S06.

[11] Metin Yetisir, Michel Gaudet, Jeremy Pencer, Michael McDonald, David Rhodes, Holly Hamilton, and Laurence Leung, “CANADIAN SUPERCRITICAL WATER-COOLED REACTOR CORE CONCEPT AND SAFETY FEATURES”, Canadian Nuclear Laboratories, Stn 42, Chalk River, ON K0j 1P0, Canada.

[12] D.F. Wang and S. Wang, "A PRELIMINARY CATHENA THERMALHYDRAULIC MODEL OF THE CANADIAN SCWR FOR SAFETY ANALYSIS”, Atomic Energy of Canada Limited, Chalk River, ON K0J 1J0, Canada.

[13] Ajoy Debbarma, K.M Pandey, Procedia Engineering 64 (2013) 507 - 517 "Numerical Analysis of Flow and Heat transfer in Subchannel of Supercritical Water Reactor".

[14] Guoli Tang, Hang Shi, Yuxin Wu, Junfu Lu, Zhouhang Li, Qing Liu, Hai Zhang, International Journal of Heat and Mass Transfer 102 (2016) 1082-1092 “A variable turbulent Prandtl number model for simulating supercritical pressure $\mathrm{CO}_{2}$ heat transfer”.

[15] Yoon Y. Bae, International Journal of Heat and Mass Transfer 92 (2016) 792-806 "A new formulation of variable turbulent Prandtl number for heat transfer to supercritical fluids”.

[16] K. Dobashi, A. Kimura, Y. Oka and S. Koshizuka, Nuclear Engineering laboratory, The University of Tokyo, Ibraki 319-11,Japan "Conceptual Design of High Temperature Power Reactor Cooled and Moderated by Supercritical Light Water".

[17] Lina Zhang, Minshan Liu, Qiwu Dong, Songwei Zhao, Energy and Power Engineering, 2011, 3, 167-173 "Numerical Research of Heat Transfer of Supercritical CO2 in Channels".

[18] Hongzhi Li, Yifan Zhang, Lixin Zhang, Mingyu Yao, Alan Kruizenga, Mark Anderson, International Journal of Heat and Mass Transfer 98 (2016) 204-218 "PDF-based modeling on the turbulent convection heat transfer of supercritical CO2 in the printed circuit heat exchangers for the supercritical CO2 Brayton cycle".

[19] Mohammad Mizanur Rahman, Ji Dongxu, Mehrdad Shahmohammadi Beni , Ho Choi Hei , Weidong He , Jiyun Zhao, Annals of Nuclear Energy 97 (2016) 53-65 "Supercritical water heat transfer for nuclear reactor applications".

[20] Dimmick, G.R., Spinks, N.J., Duffey, R., 1998. “An advanced CANDU reactor with supercritical water coolant: conceptual design features”, Proceedings of the Sixth International Conference on Nuclear Engineering (ICONE-6), San Diego, California, USA, May 10-15, Paper-6501.

[21] I.L. Pioro, H.F. Khartabil, and R.B. Duffey, "Heat Transfer to Supercritical Fluids Flowing in Channels - Empirical Correlations (Survey)”, Nuclear Engineering and Design, Vol. 230, No. 1-3, pp. 69-91, 2004. 